\title{
Adolescência, drogadição e políticas públicas: recortes no contemporâneo'
}

\author{
Adolescence, drug-addiction and public policies: \\ contemporary scenarios
}

\author{
Luciane RAUPP2 \\ Clary MILNITSKY-SAPIRO ${ }^{3}$
}

\section{Resumo}

O abuso de drogas por adolescentes é, atualmente, um grave problema de saúde pública, com consequências potencialmente danosas à sua condição peculiar de pessoa em desenvolvimento. Visando aprofundar essa questão, este trabalho investigou três instituições que recebem adolescentes usuários de drogas para tratamento. Buscou-se compreender as concepções que norteiam as práticas de tratamento nesses serviços, assim como as formas pelas quais as principais políticas públicas que prescrevem o campo estão (ou não) presentes nesses locais. A descrição etnográfica foi utilizada como método de investigação, seguida da análise de conteúdo dos diálogos informais, consultas documentais e entrevistas realizadas com profissionais e adolescentes nos locais pesquisados. Os resultados apontam uma defasagem entre o que é prescrito pelas políticas e a realidade dos serviços, ressaltando a importância de intervenções que considerem as peculiaridades da adolescência, assim como a singularidade de cada sujeito.

Unitermos: Adolescência. Drogadição. Políticas públicas.

\begin{abstract}
At the present time, drug abuse by adolescents is considered to be a serious public health issue, with potentially harmful consequences for the "peculiar conditions of a person in development". The present work aims to investigate three public institutions that accept adolescents for drug abuse treatment. The findings were compared to the adopted public policies that serve as justification for the conception of these services and investigate whether these policies practice what they preach. The Ethnographic Description was used as the method of investigation, followed by a Content Analysis of the informal dialogue, document checks, and interviews with professionals and adolescents at the locations under review. The results indicate a mismatch between what is prescribed by public policies and the actual reality of the services provided, emphasizing the importance of interventions that take the peculiarities of adolescence and individuality into account.
\end{abstract}

Uniterms: Adolescence. Drug-addiction. Public policies.

$\boldsymbol{\nabla} \mathbf{\nabla} \boldsymbol{\nabla}$

1 Artigo elaborado a partir da dissertação de L. RAUPP, intitulada "Adolescência, drogadição e políticas públicas". Programa de Pós-Graduação em Psicologia Social e Institucional, Universidade Federal do Rio Grande do Sul, 2006. Apoio: Coordenação de Aperfeiçoamento de Pessoal de Nível Superior.

2 Universidade de São Paulo, Programa de Pós-Graduação em Saúde Pública. São Paulo, SP, Brasil.

3 Universidade Federal do Rio Grande do Sul, Instituto de Psicologia, Departamento de Psicologia Social e intitucional. Av. Ramiro Barcelos, 2600, Sala 211, Campus da Saúde, 90035-003, Porto Alegre, RS, Brasil. Correspondência para/Correspondence to: C. MILNITSKY-SAPIRO. E-mail:<clarysapiro@uol.com.br>. 
Apesar de o uso de drogas ser uma prática presente desde os primórdios da humanidade, nas últimas décadas indicadores sugerem que o abuso dessas substâncias vem tomando dimensões preocupantes, por vezes trazendo sérios prejuízos à população, principalmente junto a adolescentes e adultos jovens. Considera-se que o abuso de drogas adquiriu tais dimensões devido à complexidade que envolve seu consumo e venda na atualidade. Dentre os fatores responsáveis pelo agravamento dessa questão, destacam-se os interesses econômicos envolvidos em sua produção e venda, os embates de cunho moral e ideológico em torno do uso de substâncias psicoativas, somados à baixa prioridade política conferida ao assunto, que se manifesta na insuficiência de recursos financeiros necessários para garantir uma política de educação, prevenção e tratamento, com profissionais capacitados de forma adequada e contínua (Crives \& Dimenstein, 2003).

Em um cenário propício ao aumento dos prejuízos associados ao abuso de drogas, principalmente entre os mais jovens, a questão do tratamento para adolescentes destaca-se como uma área importante, porém permeada por incertezas e dificuldades. Nesse campo não há técnicas infalíveis, a produção de conhecimento específico é relativamente pequena e a efetividade dos programas é baixa (Kaminer \& Szobot, 2004).

Considerando a importância desta questão, este estudo visou descrever diferentes formas de enfrentamento ao abuso e dependência de drogas na adolescência, partindo do entendimento de que a produção acadêmica deve implicar a análise e proposição de respostas aos problemas contemporâneos. A partir da descrição etnográfica (Loss \& Milnitsky-Sapiro, 2005; Menegaz \& Milnitsky-Sapiro, 2002; Milnitsky-Sapiro, 2001) de diferentes programas de atendimento a adolescentes usuários de drogas da cidade de Porto Alegre, destacam-se alguns dos resultados de uma pesquisa de mestrado que objetivou comparar as concepções presentes nas principais políticas públicas vigentes nesse campo com as práticas encontradas nos serviços pesquisados.

Os resultados indicaram que, apesar dos importantes avanços obtidos na atenção ao adolescente após a promulgação do Estatuto da Criança e do Adolescente (Brasil, 1994), o cotidiano dos jovens do país demonstra que a Doutrina da Proteção Integral é ainda muito mais

446 um desafio do que uma realidade. Nesse sentido, o tratamento da drogadição para adolescentes destaca-se como uma "questão-problema", devido à escassez de locais adequados e de profissionais capacitados para atender às demandas singulares desse público, que, muitas vezes, é encaminhado para tratamento em locais planejados para adultos e não atualizados com as orientações das principais políticas públicas do setor.

\section{Os adolescentes e o abuso de drogas na sociedade contemporânea}

Este estudo teve como eixo norteador o entendimento de que o tratamento da drogadição é especialmente complexo na adolescência. Embora haja uma carência de trabalhos específicos sobre esta questão, assim como de pesquisas com adolescentes usuários de drogas, sabe-se que o uso de drogas nesta fase distingue-se do uso em outras etapas do desenvolvimento (Kessler et al., 2003).

Na adolescência, o recurso às drogas deve ser compreendido como essencialmente ligado às várias operações psíquicas atuantes nesta fase. Isso pode implicar que o uso de substâncias psicoativas se torne um comportamento relativamente comum nessa etapa - especialmente entre grupos expostos a importantes fatores de risco, tais como alta disponibilidade de drogas, ambiente comunitário desprovido de acesso a bens culturais, esportivos etc., abandono da escola, problemas familiares, entre outros.

Entre os autores que estudam a adolescência, há uma concordância quanto a esse ser um período que envolve várias e difíceis mudanças, que requerem novas elaborações psíquicas e reposicionamentos do sujeito frente às mudanças corporais, à reedição de conflitos infantis e às novas exigências que lhe advêm, tanto interna quanto externamente. De acordo com Rassial (1997), o adolescente está sempre em risco de "entrar em pane", porque ele precisa realizar uma série de "operações fundadoras". É como se o sujeito se encontrasse frente a um hiato no qual, de um lado, está a sua condição infantil e identificações familiares e, do outro, novas e atraentes possibilidades identificatórias disseminadas no social. Desta forma, o adolescente ocupa uma "posição no intervalo", na qual, por não ser mais criança e tampouco ser adulto, atravessa um período de indecisão subjetiva e de incerteza social que 
adquire as características de uma verdadeira crise psíquica (Rassial, 1997, p. 70).

Segundo Torrosian (2002), frente às mudanças que ocorrem na adolescência as castrações são reativadas, e surge uma forte necessidade de buscar meios para lidar com os conflitos daí decorrentes. Além disso, durante a adolescência o ego se apresenta altamente instável e vulnerável às influências externas (Levisky, 1997); nesse sentido, embora a maioria dos jovens seja contra o uso de drogas, muitos se deixam levar pela chamada pressão do grupo (X.S. Silveira \& E.D. Silveira, 1999), especialmente em uma sociedade na qual o consumo de objetos é o principal meio para a aquisição de status e poder, e a busca por satisfação imediata é um dos valores mais cultivados.

Nesse contexto, a exposição e a convivência com as drogas constituem um duplo desafio. Para o adolescente, o desafio é representado pelo fácil acesso à transgressão e à fuga dos conflitos inerentes a esta fase; para a sociedade, é representado pela convocação à criação de dispositivos políticos e legais capazes de oferecer novas formas de visibilidade, identificação e inserção social a esses jovens, assim como serviços e profissionais capacitados a atender às suas demandas.

O foco nas relações psíquicas e sociais envolvidas na questão da drogadição na adolescência é importante para a elaboração de qualquer programa de atenção a esse público. Contudo, para uma análise acurada dessas iniciativas, torna-se necessário aliar essa temática ao estudo das principais políticas públicas que prescrevem o campo, a fim de explicitar as diretrizes que deveriam balizar os programas de atenção.

\section{As políticas públicas}

Visando comparar as práticas dos serviços pesquisados com as diretrizes oficiais desse campo, procedeu-se ao levantamento das principais políticas públicas (PP) que o compõem. Na sequência, serão abordadas as orientações do Estatuto da Criança e do Adolescente, da Política do Ministério da Saúde e da Política Nacional Antidrogas, principais orientações da área, focando nos itens importantes para este estudo.

Dentre as PP que estabelecem ações voltadas à atenção de adolescentes, o Estatuto da Criança e do Adolescente (Brasil, 1994) é a diretriz fundamental, e deve ser respeitado em qualquer projeto de atenção a esse público. Esse texto aborda o encaminhamento de adolescentes usuários de drogas para tratamento como uma medida específica de proteção, estabelecendo seu direito e prioridade em receber atendimento. Segundo o artigo 101, toda criança ou adolescente nessa situação deve "receber orientação, apoio e acompanhamento temporários; requisição de tratamento médico, psicológico ou psiquiátrico, em regime hospitalar ou ambulatorial, ou inclusão em programa oficial ou comunitário de auxílio, orientação e tratamento a alcoólatras e toxicômanos" (Brasil, 1994, p.36). Essas medidas também são aplicáveis aos pais ou responsáveis e são atribuições do Conselho Tutelar.

No que se refere às PP de atenção específica aos problemas relacionados ao uso de álcool e outras drogas, a Política de Atenção Integral ao Usuário de Álcool e Outras Drogas (Brasil, 2004) é a diretriz principal na área da saúde pública. Essa política tem nos princípios do Sistema Único de Saúde (SUS) e da Reforma Psiquiátrica seus eixos centrais, a partir dos quais trabalha as especificidades de seu público-alvo. Suas principais orientações visam: o estabelecimento e fortalecimento de um trabalho em rede, para proporcionar uma atenção integral, nos moldes da intersetorialidade; garantir acesso facilitado aos serviços; participação do usuário no tratamento; e a criação de serviços de atenção diária como alternativa ao hospital psiquiátrico - os Centros de Apoio Psicossocial (CAPS) -, segundo o paradigma da Reforma Psiquiátrica.

Além do Ministério da Saúde, outro órgão governamental responsável pelas diretrizes relativas ao controle do impacto das drogas na sociedade brasileira é a Secretaria Nacional Antidrogas (SENAD), que atua na redução da oferta e da demanda de drogas no país e é responsável pela Política Nacional Sobre Drogas (Brasil, 2005). Suas principais diretrizes visam: atingir o ideal de construção de uma sociedade protegida do uso de drogas; reconhecer o direito de toda pessoa receber tratamento para drogadição; reconhecer as diferenças entre o usuário, a pessoa em uso indevido, o dependente e o traficante; priorizar ações de prevenção; incentivar ações integradas aos setores de educação, saúde e segurança pública; promover ações de redução de danos; garantir ações para reduzir a oferta de drogas no país, entre outras orientações. 


\section{Método}

\section{Participantes}

Foram pesquisadas três instituições especializadas no atendimento da dependência química: um ambulatório municipal; uma unidade especializada de um hospital geral; e uma Comunidade Terapêutica. Além do trabalho de observação, foram entrevistados dois profissionais e três adolescentes em cada local: a freira coordenadora e um estudante de Psicologia, na Comunidade Terapêutica; um psicólogo e um assistente social, na unidade de dependência química; e uma psicóloga e uma terapeuta ocupacional, no ambulatório municipal.

\section{Instrumentos}

Na coleta de dados realizou-se uma descrição de cunho etnográfico (Milnitsky-Sapiro, 2001; Menegaz \& Milnitsky-Sapiro, 2002; Loss \& Milnitsky-Sapiro, 2005) das instituições, através do emprego de observação participante, cujas observações efetuadas foram registradas em um diário de campo; consulta a documentos disponíveis (prontuários, estatutos e material de divulgação); e entrevistas semi-estruturadas com questões abertas visando conhecer a trajetória de cada entrevistado, sua opinião acerca do serviço e sugestões para sua melhoria.

\section{Procedimentos}

As instituições pesquisadas foram selecionadas a partir de indicações do Conselho Municipal de Entorpecentes de Porto Alegre. Após um contato inicial com cada local, a fim de explicar a pesquisa e obter autorização por escrito para a mesma, iniciou-se a coleta de dados. Esta durou cerca de um mês em cada instituição com a pesquisadora responsável comparecendo semanalmente a todas as atividades desenvolvidas, a fim de observar sua rotina e proceder ao registro das mesmas no diário de campo. Considera-se que o emprego da descrição de cunho etnográfico permitiu uma "imersão" nos locais de pesquisa, facilitando a compreensão dos funcionamentos e diferenças existentes em cada instituição.

As entrevistas foram realizadas pela pesquisadora em salas privativas localizadas nas próprias instituições. O tempo de aplicação foi, em média, de 40 minutos, com o material registrado em fita cassete. Os entrevistados foram selecionados a partir dos critérios de disposição em participar da pesquisa, voluntariedade, anonimato, tempo mínimo de um mês de tratamento (para os adolescentes) e assinatura de Termo de Consentimento Esclarecido e Informado.

A análise dos dados se deu através da utilização do método de Análise de Conteúdo (Bardin, 1977). Durante este procedimento, foram identificados temas emergentes a partir do trabalho de campo e das entrevistas realizadas, os quais delinearam a constituição de categorias e suas subseqüentes interpretações

\section{Resultados}

Os resultados emergentes a partir da triangulação dos dados coletados serão apresentados a seguir, com foco na descrição das instituições pesquisadas, suas abordagens e concepções de tratamento. Trechos das entrevistas realizadas exemplificarão cada categoria abordada.

\section{Descrição das instituições}

A primeira instituição pesquisada foi uma Comunidade Terapêutica (CT) ${ }^{4}$ que recebe jovens do sexo feminino entre 12 e 30 anos de idade. Esse local foi fundado na década de 1990 pela Igreja Católica, ocupando as instalações de uma antiga escola. Era administrado por quatro freiras; uma delas era a coordenadora geral e as demais eram responsáveis pela organização das rotinas e sua execução. Nenhuma das freiras possuía escolaridade de nível superior ou alguma formação específica, fora a religiosa. A equipe contava com vários

\section{$\boldsymbol{\nabla} \boldsymbol{\nabla} \boldsymbol{\nabla}$}

- Modalidade de atenção surgida na Grã-Bretanha na década de 1940. Foi inicialmente utilizada para o tratamento de pacientes psiquiátricos crônicos, e só posteriormente adaptada para o tratamento da drogadição. Atualmente, existe como uma opção de tratamento que se desenvolve à margem das 
voluntários que ministravam atividades em grupo junto às residentes, entre os quais um médico psiquiatra e uma ginecologista que compareciam no local quando solicitados para algum atendimento específico. Cabe ressaltar que nenhum dos técnicos citados era responsável pelo programa terapêutico da CT ou funcionário fixo do local, conforme estabelece a Resolução no 101 da Agência de Vigilância Sanitária (ANVISA), que estabelece as normas de funcionamento para as CT no País. O tratamento era custeado pelas famílias, mediante contribuições mensais de acordo com a renda familiar.

O segundo local estudado foi uma unidade de dependência química, pertencente a um hospital geral de Porto Alegre, considerada uma referência na área há mais de dez anos. Comportava dois setores distintos e interligados: o ambulatório e a internação, ambos com atendimento para pacientes privativos e do SUS, de ambos os sexos, maiores de 15 anos, em sua maioria adultos - embora, segundo os entrevistados, sempre contasse com adolescentes entre seu pacientes. Em sua equipe havia psiquiatras, psicólogos, assistente social, profissionais de enfermagem, recepcionistas e estagiários.

O terceiro local pesquisado foi um ambulatório especializado no atendimento de adolescentes, integrante da rede especializada de saúde mental da prefeitura. Suas instalações ocupavam metade de uma Unidade Básica de Saúde. Oferecia atendimento a jovens de 12 a 21 anos incompletos, vítimas de violência doméstica, urbana, sexual ou usuários de drogas. Seu público era, majoritariamente, composto por adolescentes encaminhados por órgãos de proteção, tais como o Conselho Tutelar e a Fundação de Atendimento Socioeducativo (antiga FEBEM). Sua equipe era composta por psicólogas, terapeuta ocupacional, médico clínico, psicopedagoga, auxiliar de enfermagem, recepcionista, estagiários e residentes.

\section{Objetivos e métodos empregados}

A seguir serão explicitadas as modalidades e objetivos dos tratamentos oferecidos em cada serviço pesquisado, assim como as orientações que os norteiam.

O tratamento na CT ocorria em modalidade de internação, pelo período mínimo de nove meses. Seu programa terapêutico baseava-se em um cronograma diário de atividades, dividido em: laborterapia (atividades diárias de limpeza e organização da comunidade); atividades religiosas e oficinas ministradas por voluntários (trabalhos manuais, música, recreação, grupos de autoajuda e evangelização). Nos relatos abaixo a coordenadora da CT esclarece as orientações e objetivos que regem o trabalho:

Nosso critério é: espiritualidade, trabalho e disciplina.... Todo o programa da casa éimportante: a realização dos 12 passos, os grupos, os princípios de Amor Exigente, a Laborterapia; todos os trabalhos que se passam na casa são terapêuticos, visando à recuperação e à reeducação delas (das adolescentes).

Oobjetivo é trabalhar na reeducação das adolescentes, corrigir aquilo que elas faziam de maneira errada na rua, através do programa terapêutico.

O tratamento na unidade de dependência química abrangia duas modalidades distintas de atenção: o ambulatório e a internação. O setor de ambulatório oferecia psicoterapia individual, atendimentos em grupo, prescrição de medicamentos e exames para a detecção de uso de drogas. Nesse setor, o adolescente recebia atendimento e retornava à suas atividades cotidianas. Já no setor de internação, a atenção era de caráter intensivo, ou seja, o adolescente ficava em tempo integral na unidade, de dez a trinta dias (dependendo de seu convênio), submetendo-se às suas regras e a um cronograma fixo de atividades diárias. Seu programa terapêutico baseava-se em três pontos centrais: atividades físicas e recreativas, atendimentos em grupo e atenção às famílias. Ambos os setores tinham como objetivo principal motivar os pacientes para o alcance e a manutenção da abstinência de drogas, como esclarece o psicólogo entrevistado:"Nós temos o papel de motivar as pessoas a quererem parar de usar drogas, não adianta aceitarmos somente pacientes que já queiram parar. Então, uma das linhas que a gente trabalha na área de dependência química é a motivacional, é motivar o paciente a parar realmente".

No relato abaixo, o assistente social da unidade esclarece a sua abordagem:"A gente tem uma abordagem aqui mais cognitiva; é cognitivo-comportamental".

Na terceira instituição pesquisada, o ambulatório municipal, a atenção era de caráter continuado e não intensivo, ou seja, o adolescente permanece em tratamento sem ser afastado de sua rotina. O serviço oferecia 
atendimentos individuais e grupais, divididos entre psicoterapia individual, atendimento médico, terapia ocupacional, atendimentos em grupo (grupos para adolescentes de até 14 anos e grupos para maiores de 15 anos) e acompanhamento psicopedagógico. A principal abordagem desse serviço é a redução de danos, como demonstra o trecho a seguir, no qual a psicóloga entrevistada descreve a dinâmica dos grupos para adolescentes:

Geralmentenos meus grupos eles têm ouso de maconha eloló. Eles mesmosjá trazem a ideia de querer largar o loló ejá vão reduzindo ... Então, eu trabalhava assim, na fala deles mesmos: 'Larguei o loló e tô melhor, eu só tô com a maconha'; aí o grupo mesmo vai dizendo: 'Ah não, tem que largar a maconha também, se deu pra largar o loló dá pra largar a maconha também!' E geralmente eles vão parando, até porque eles têm esse acompanhamento sistemático. Trabalhamos assim, conforme eles vão trazendo. A gente dá ênfase numa ou noutra coisa, mas a redução éfeita assim, por eles mesmos, por escolha deles.

Além dos atendimentos descritos, o ambulatório contava também com projetos de reintegração social, nos quais alguns adolescentes em tratamento eram vinculados a programas de estágios e geração de renda, por meio do estabelecimento de um trabalho em rede com outros setores da prefeitura, conforme esclarece a terapeuta ocupacional:

A gente acabou vendo que tem que incluir, dar outra oportunidade, não adianta tu só dar atendimento terapêutico, chega o momento em que o cara tá num sofrimento psíquico porque precisa trabalhar ... . Então, como a gente não tinha uma rede para fazer parcerias, começamos a criar essa rede; por exemplo, ano passado fizemos uma proposta pra Secretaria de Administração praque pudéssemos encaminharos adolescentes triados por nós para os estágios para a prefeitura de Porto Alegre, e isso deu certo.

\section{Concepções sobre os adolescentes}

Nesta categoria, busca-se explicitar as concepções dos profissionais acerca dos adolescentes e de suas principais necessidades, a partir do entendimento de que tais concepções estão relacionadas às práticas de tratamento dos locais pesquisados.

Em vários trechos das entrevistas realizadas na $450 C T$, constatou-se a presença de uma associação entre uso de drogas, negligência familiar e falta de orientação apropriada. Segundo a coordenadora, quando as adolescentes se deparam com a obrigação de cumprir o cronograma de tarefas da casa, percebe-se que apresentam grandes dificuldades no desempenho de tarefas básicas, como higiene pessoal ou organização da casa; por isso ela considera que as mesmas não sabem fazer nada, só o que é "errado" e, portanto, necessitam de limites e reeducação:

Todas as adolescentes que são encaminhadas pra casa
têm um comportamento anterior quejá era uma droga.
Elas não sabem fazer nada, só aquilo queé errado.

Então o que nós precisamos, é ter coragem para impor limites a elas, com toda caridade e entendendo o lado dessas adolescentes, por que são todas meninas que tiveram marcas em sua infância de rejeição, espancamento, violência, e que hoje precisam ser amadas, corrigidas e ensinadas, porque não sabem nada, só aquilo que é errado... . Precisamos fazer isso com firmeza e colocando limites.

Segundo os profissionais da unidade de dependência química, os adolescentes precisam de suporte, limites, rotina e espaços de tratamento adequados a eles:

Eu vou falar uma coisa meio óbvia, assim: falta limite. A necessidade deles às vezes é chegar alguém aqui e ter alguém que dêum suporte. Eu vejo também que eles têm necessidades de uma coisa mais física, uma certa rotina. ... Eles têm necessidades bem diferentes dos adultos.

Eu entendo que seja outro tipo de acolhida que esse público necessita ... . A gente também tem uma dificuldade de material; mas eu acho que essa parte mais lúdica do esporte, atividade corporal, eu acho que é necessário tentar mostrar coisas que podem também gerar prazer e desafiá-los a buscar algo diferente.

Já os profissionais do ambulatório municipal enfatizaram as questões sociais ligadas ao adolescente com problemas relacionados ao uso de drogas, que requerem uma atenção por parte da equipe que vá além dos atendimentos clínicos usuais, conforme expõe abaixo a terapeuta ocupacional:

Éum adolescente que tá vinculado ao tráfico de drogas, à questão do ato infracional; muitas vezes com uma certa idealização, querendo estar ali...; só que outros acabam entrando por uma pressão de falta de oportunidades, mesmo... . Então, isso é uma coisa que a gente tá vendo, que tem que ter uma ocupação, que eles precisam 
também de oportunidades de geração de renda, de acompanhamento com a pedagoga, pois têm toda uma vidaláfora.

\section{A opinião dos adolescentes}

Todas as adolescentes em tratamento na CT referiram que, apesar das dificuldades de relacionamento e dos conflitos existentes, sentiam-se "acolhidas", "ensinadas", ajudadas" e "compreendidas", avaliando positivamente a instituição e, inclusive, considerando que a equipe deveria ser ainda mais exigente.

A experiência aqui é muito boa, porque as pessoas me ajudam e me entendem e eu ajudo as pessoas também a se conhecerem mais. Te traz uma paz, uma tranquilidade.

Eu acho que precisava ser mais rígido. A gente tem que aprendero queécorreto. Eu acho quenovemesesépouco ainda pra uma pessoa nascer de novo, mas, sabe, é apavorante nove meses.

No que se relaciona à avaliação do tratamento recebido na unidade de dependência química, os adolescentes avaliaram-no positivamente, principalmente quanto à atenção disponibilizada pela equipe e à importância de estar em um ambiente estruturado, com regras e horários: "No começo eu não gostava porque era muito trancado, mas agora tu pode pegar o teu sol, tem atividades pra fazer, tô achando proveitoso". "Tem que acordar cedo, né? Pra tomar café da manhã, horário pra tudo. Mas, normal, até acho que agora vou acostumar a dormir cedo e acordar cedo".

Por outro lado, seus relatos demonstram também certa descrença na efetividade do tratamento para uma recuperação duradoura; além do fato de que um dos adolescentes estava em tratamento pela quinta vez no mesmo local e ainda não se considerava recuperado, mesmo após tantas internações:

Cinco internações no mesmo lugar. Vai fazer dois anos que eu venho pra cá... . Mas aos poucos eu tô melhorando, aos poucos; eu não melhorei ainda o bastante, mas eu tô melhorando.... Porque eu não tô aqui só por minha causa, mas por causa deles também [seus pais]; mas acho que se eles não me ajudarem, minha vida vai tomar um rumo diferente do que eu pretendo tomar, largar de mão, sabe, viver uma vida, sei lá, de um viciado, voltar pras drogas, crime, esse tipo de coisa.
Onegócio é coloca na tua cabeça que tu não quer mais usardroga, porque se tu virpra cá gostando da coisa, não adianta, não vai te dar um choque que tu tem que parar.

Os adolescentes do ambulatório municipal avaliaram positivamente os efeitos do tratamento, ressaltando a importância de ser acolhido e ter com quem conversar: "É bom, porque é legal vir conversar com a psicóloga, ela limpa a cabeça do cara, sabe, ela dá uns conselhos bons, me ajuda em várias coisas". "Fez toda diferença. Eu não parava em casa, agora eu paro, faço um monte de coisa, tô mais calmo, antes eu era muito nervoso".

No entanto, apesar das melhorias de gostarem do tratamento, os três adolescentes entrevistados atribuíram sua recuperação a outros fatores, tais como o apoio da família, o tratamento medicamentoso e as responsabilidades de ter um filho:

Oque mais me ajudou foi o impulso da minha mãee os
remédios.

Depois que eu ganhei a nenê eu não usei mais, vaifazer um ano. Não foi difícil, porque eu tava consciente quese eu continuasse com a droga eu ia perder a minha filha. Então eu largueipor causa da minha filha e sabendo que era uma coisaboa.

\section{Resultados e Discussão}

Dada a diversidade de práticas e concepções de tratamento encontradas nos locais pesquisados, considera-se que esse estudo captou a heterogeneidade predominante nesse campo, pois cada local pesquisado pertence a uma modalidade representativa da realidade dos serviços de tratamento da drogadição na atualidade.

Em dois dos três locais pesquisados, os programas terapêuticos tinham como base o alcance da abstinência, contrariamente às orientações das PP citadas, que estabelecem as estratégias de redução de danos como uma diretriz nacional. Também nesses dois serviços não havia programas específicos para os adolescentes, que participavam de atividades planejadas para adultos, e geralmente não contavam com espaços de escuta individual. Apenas o ambulatório municipal possuía um programa planejado para adolescentes, buscando contemplar as especificidades desta fase e atender às diretrizes do Ministério da Saúde, tais como 
trabalhar em rede, buscar uma integralidade na atenção e adotar estratégias de redução de danos.

No intuito de apreender os efeitos dessas abordagens, a seguir serão mencionados os resultados obtidos nas três instituições pesquisadas, buscando-se explicitar as principais concepções norteadoras de suas práticas de tratamento.

A descrição etnográfica realizada na CT implicou uma imersão no seu cotidiano, fundamental para a compreensão de uma instituição tão diferenciada. 0 tempo prolongado de internação, o estatuto de "residente" dado às adolescentes, a ausência de técnicos fixos e a influência religiosa - que se fazia presente em todo o ambiente, por exemplo, em sua estrutura física (capela, imagens religiosas), atividades (orações pela manhã, antes das refeições e à noite, catequese, crisma, missas etc.) e regras - são exemplos da peculiaridade desta modalidade.

Conforme demonstraram as entrevistas, o objetivo principal do tratamento na CT não se restringia ao alcance da abstinência de drogas, mas visava algo que a continha e ultrapassava, denominado pela coordenadora da instituição como "reeducação" e transformação das adolescentes. Nesse sentido, seus principais instrumentos terapêuticos (disciplina, espiritualidade cristã e princípios de autoajuda) eram utilizados como meios para viabilizar esse processo, ao transmitir valores, estabelecer "limites" e "moldar"as residentes à aquisição de novos comportamentos e outro estilo de vida.

Ao lado da orientação educacional, outra característica marcante da CT era o seu clima familiar e religioso, que proporcionava acolhimento, atenção e satisfação de necessidades básicas, conforme atestam as adolescentes em seus relatos. Se considerarmos o caráter de "crise" da fase adolescente, somado às instabilidades provocadas pela organização social atual, agravadas pela situação de desamparo na qual as jovens chegavam à CT, pode-se compreender a importância de ser cuidado, protegido e contido em um ambiente estruturado, com características "familiares", no qual, para muitas das residentes, pela primeira vez havia pessoas interessadas em seu desenvolvimento. Além disso, quando um ambiente oferece condições de continência, facilita que as pulsões do adolescente - tensas e turbulentas - sejam reconfiguradas em enquadra-

452 mentos mais bem definidos, nos quais possam encon- trar maiores possibilidades de estabelecer sistemas internos de equilíbrio e interação social (Levisky, 2005).

Considerando as características acima referidas, conclui-se que o programa terapêutico da CT corresponde ao "modelo moral" de tratamento, o viés mais tradicional nesse campo, segundo o modelo proposto por Marlatt e Gordon (1993). Nessa perspectiva, fortemente embasada na moralidade cristã, o uso excessivo de drogas é compreendido como um problema de controle do impulso, no qual falta ao indivíduo força de vontade e "fibra moral" para mudar seu comportamento e resistir à tentação (Marlatt \& Gordon, 1993). Considera-se que o tratamento na CT corresponde a esse modelo por ter na doutrina cristã seu cerne, e por sua rotina de atividades estar estruturada de forma a controlar os impulsos das adolescentes e seu comportamento, trabalhando de forma intensiva suas capacidades de postergar, substituir e reprimir seus impulsos. A "laborterapia" é uma das atividades que mais contribuem nesse processo, ao inserir as jovens em atividades obrigatórias com grande carga horária, que devem ser executadas com precisão. Toda a orientação educativa e familiar da CT atua, basicamente, a partir de dois aspectos centrais: a disciplina e a reeducação, visando ao"renascimento" das adolescentes em uma nova ordem moral.

De forma distinta da abordagem religiosa/moral predominante na CT, o tratamento na unidade de dependência química do hospital geral pode ser compreendido a partir do que Marlatt e Gordon (1993) conceituaram como "modelo de doença" ou "modelo médico". De acordo com esta abordagem, predominante nesse campo, o abuso e a dependência de álcool e outras drogas são causados por uma dependência física subjacente, que se relaciona a fatores biológicos e ambientais predisponentes.

Tendo por base esse modelo, todos os adolescentes em tratamento no local estudado recebiam cuidados médicos e terapia farmacológica, principalmente os que estavam na unidade de internação. 0 foco da atenção centrava-se na substância psicoativa e seus efeitos farmacológicos, sem que houvesse muito espaço para a consideração de questões psíquicas ou sociais. De acordo com Cruz (2000), nessa abordagem procura-se estender para o campo da drogadição paradigmas que obtiveram êxito no tratamento de outras 
formas de adoecimento, segundo modelos epidemiológicos que generalizam os fatores causadores da "doença".

Estreitamente ligadas a essa concepção, as técnicas cognitivo-comportamentais eram empregadas na unidade estudada como o principal instrumento terapêutico para a aprendizagem de formas de controlar a "doença" e manter a abstinência. Nesse sentido, os achados deste estudo corroboraram a afirmação de Cruz (2000) no que diz respeito à frequente aliança no campo entre as terapias comportamentais e o "modelo médico". Cabe ressaltar que um dos profissionais entrevistados sublinhou as dificuldades de aplicar a terapia cognitiva ao tratamento de adolescentes, dado que o tratamento na unidade de dependência química estudada não foi concebido para este público.

No que diz respeito à avaliação do tratamento recebido na unidade, os adolescentes participantes da pesquisa avaliaram-no positivamente, principalmente quanto à importância de estar em um ambiente estruturado. No entanto, seus relatos denotaram também uma descrença no tratamento como meio efetivo para o alcance de uma recuperação duradoura.

Segundo os dados desta pesquisa, podem-se apontar deficiências nesta abordagem, principalmente no tocante à indicação da internação como modalidade única de atenção, sem o necessário acompanhamento pós-alta. Cabe ressaltar que essa continuidade era incentivada pela equipe da unidade, contudo nem sempre era possível, especialmente para pacientes de baixa renda. Segundo Kaminer e Szobot (2004), o tratamento de adolescentes em unidades fechadas deveria ser uma exceção reservada a situações extremas, tais como risco de suicídio ou homicídio, uso grave e descontrolado da droga, condutas de risco, surto psicótico, grave conflito com a lei ou outras ameaças.

Já no ambulatório municipal especializado no atendimento de adolescentes, que não visava exclusivamente o tratamento da drogadição - pois seus objetivos incluíam também a atenção a vítimas de violência - nota-se que o público era composto, em sua maioria, por adolescentes oriundos de famílias de baixa renda, o que talvez explique os esforços dos profissionais entrevistados para compreender seu público e aproximar-se do seu universo de relações.
No que se refere à abordagem que norteava o tratamento no ambulatório, pode-se afirmar que a mesma correspondia aos pressupostos da redução de danos, por não impor um modelo único de recuperação e não visar à abstinência de drogas como objetivo único do tratamento. Nas observações efetuadas e nas entrevistas percebeu-se que a equipe buscava adaptar a atenção às particularidades de seu público e ao que Ihes era viável, enfatizando a sua autonomia. Um exemplo da aplicação da redução de danos foi citado no relato da psicóloga do ambulatório, que afirmava serem os encontros em grupo conduzidos pelos próprios adolescentes, os quais faziam a redução por si mesmos.

Apesar de essa abordagem apelar menos para um ideal de saúde do que para aquilo que é viável ao sujeito e, portanto, não exigir a abstinência, Marlatt (1999) ressalta que esta é uma meta desejável, porém situada em um continuum que não dicotomiza as possibilidades de recuperação. Cabe ressaltar que os adolescentes participantes da pesquisa não estavam usando drogas na época da coleta de dados, o que pode indicar que essa abordagem também conduziria ao alcance da abstinência após um longo prazo. Nas entrevistas os adolescentes referiram que esse resultado não adveio do sucesso da aplicação de estratégias terapêuticas específicas, mas foi uma consequência de mudanças em diversos aspectos de suas vidas, tais como relações familiares, melhoria em outros sintomas ou o incremento de sua "força de vontade". Tais achados podem indicar que o tratamento produziu efeitos, principalmente pela capacidade de apoiar e conter os adolescentes por um longo período, possivelmente auxiliando-os na elaboração de conflitos psíquicos e servindo de lugar de referência e passagem, mesmo quando se sentiam perdidos e incapazes de elaborar suas experiências por outra via que não a tóxica.

Outro aspecto importante relacionado ao trabalho do ambulatório refere-se à prática de conexão com outras instâncias, corroborando as diretrizes das PP do setor. Nos relatos das profissionais são explicitados seus esforços para estabelecer um trabalho em rede com outros serviços, a fim de oportunizar ao adolescente a vivência de novas formas de inserção social e de trânsito por diferentes possibilidades de formação de sua identidade. 


\section{Considerações Finais}

É importante finalizar este artigo ressaltando que não existem "fórmulas mágicas" nem tratamentos infalíveis para lidar com uma questão tão complexa quanto a drogadição na adolescência. Por esta razão, este estudo buscou dar visibilidade a diferentes concepções e práticas de atenção, visando, principalmente, problematizar o lugar destinado ao adolescente em cada serviço pesquisado.

De uma forma geral, os resultados indicaram a importância da problematização dos modelos de atenção ao adolescente, que tendem a individualizar o problema do abuso de drogas desconsiderando outros determinantes fundamentais do problema. Nesse sentido, sublinha-se que o predomínio do "modelo de doença" nos tratamentos pode levar a uma ênfase excessiva na questão da dependência química, negligenciando as motivações inconscientes dos sujeitos, assim como o papel do meio social na instalação das dependências. Por outro lado, a análise efetuada na CT demonstrou o potencial desses espaços na recuperação de adolescentes desprovidos de recursos que facilitem o sucesso do tratamento. Devido a algumas limitações constatadas no local pesquisado, tais como a falta de um programa terapêutico específico para cada adolescente e a ausência de profissionais especializados, conclui-se que as $\mathrm{CT}$ devem receber maior atenção e investimentos, pois vêm ocupando um lugar importante nesse campo. Se as orientações das políticas públicas do setor fossem efetivamente adotadas e fiscalizadas, poder-se-ia investir na qualificação das CT existentes, aproveitando melhor seu potencial.

Acima de tudo, considera-se que esta pesquisa aponta a importância de que os tratamentos, independentemente da modalidade de atenção, não se restrinjam ao alcance da abstinência, mas visem à produção de mudanças nas relações que os adolescentes estabelecem com as drogas em suas vidas, operando mudanças em suas posições subjetivas ao promover sua autonomia, ao invés de enfatizar sua dependência.

\section{Referências}

Bardin, L. (1977). Análise de conteúdo. Lisboa: Edições 70.

Brasil. (1994). Estatuto da criança e do adolescente. São Paulo: 454
Brasil (1995). Política nacional sobre drogas. Recuperado em abril 10, 2007, disponível em www.senad.gov.br

Crives, M. N. S., \& Dimenstein, M. (2003). Sentidos produzidos acerca do consumo de substâncias psicoativas por usuários de um Programa Público. Saúde e Sociedade, 12, 19-25.

Cruz, J (2000). Práticas médicas e toxicomanias. In G. Acselrad (Org.), Avessos do prazer: drogas, AIDS e direitos humanos. São Paulo: Fiocruz.

Cruz, W. F. (2003). Intoxicação e exclusão social. Revista da Associação Psicanalítica de Porto Alegre, 13 (24), 19-39.

Kaminer, Y., \& Szobot, C. (2004). O Tratamento de adolescentes com transtornos por uso de substâncias psicoativas. In L. Pinsky \& M. A. Bessa (Orgs.), Adolescência e drogas. São Paulo: Editora Contexto.

Kessler, F., von Diemen, L., Seganfredo, A. C., Brandão, I., Saibro, P., Scheidt, B., et al. (2003). Psicodinâmica do adolescente envolvido com drogas. Revista de Psiquiatria do Rio Grande do Sul, 25 (1), 19-26.

Levisky, D. L. (1997). Adolescência e violência: conseqüências da realidade brasileira. Porto Alegre: Artes Médicas.

Loss, M., \& Milnitsky-Sapiro, C. (2005). Processos psíquicos do engravidamento na adolescência em contextos de periferia: impasses e possibilidades. Revista de Psicologia da USP, 16 (4), 69-99.

Mager, M., \& Silvestre, E. (2004). Mitos e verdades sobre o estatuto da criança e do adolescente. In L. Pinsky \& M. A. Bessa (Orgs.), Adolescência e drogas (pp.79-91). São Paulo: Editora Contexto.

Marlatt, A., \& Gordon, J. (1993). Prevenção à recaída. Porto Alegre: Artes Médicas.

Marlatt, A. (1999). Redução de danos: estratégias práticas para lidar com comportamentos de alto risco. Porto Alegre: Artes Médicas.

Menegaz, C. V., \& Milnitsky-Sapiro, C. (2002). Capricho ou oráculo: representações na imprensa sobre adolescentes. Revista de Ciências Humanas, 6, 161-174.

Milnitsky-Sapiro, C. (2001). Uma metodologia para a formação de um profissional da área da saúde comprometido com a realidade social. Anais do 40 Seminário de Metodologia de Projetos de Extensão e da 4a Jornada Científica da UFSCar-IV SEMPE. São Carlos.

Brasil. Ministério da Saúde. (2004). A política do Ministério da Saúde para atenção integral a usuários de álcool e outras drogas. Brasília: CN-DST/AIDS.

Rassial, J. J. (1997). A passagem adolescente: da família ao laço conjugal. Porto Alegre: Artes e Ofícios.

Silveira, X. S., \& Silveira, E. D. (1999). A família e as drogas. In E. M. Seidl, L. F. Costa \& M. F. O. Sudbrack (Orgs.), Prevenção ao uso indevido de drogas: diga sim à vida. Brasília: Secretaria Nacional Anti-Drogas.

Torossian, S. D. (2002). A construção das toxicomanias na adolescência: travessias e ancoragem. Santa Cruz do Sul: Edunisc.

Recebido em: 12/6/2006

Versão final reapresentada em: 9/6/2007

Aprovado em: 10/9/2007 